\title{
Mediastinal and Pericardial Hydatidosis-A Case Report and Review of Literature
}

\author{
Subha Narayan Panda \\ Department of Cardiology, Queens NRI Hospital, Visakhapatnam, Andhra Pradesh, India \\ Email: panda.subha@rediffmail.com
}

Received 16 March 2016; accepted 26 June 2016; published 29 June 2016

Copyright (C) 2016 by author and Scientific Research Publishing Inc.

This work is licensed under the Creative Commons Attribution International License (CC BY). http://creativecommons.org/licenses/by/4.0/

(c) (i) Open Access

\begin{abstract}
Hydatid disease caused by Echinococcus granulosus is endemic in Indian subcontinent and a common surgical problem. Although occurrence of hydatid cyst is common in liver and lungs, it can be encountered in almost every part of the body. Combined mediastinal and pericardial hydatid disease is a rare occurrence and only a few cases have been reported in the literature. Patients with hydatid cysts are usually asymptomatic. Our case report demonstrates a 57-year-old female patient who presented with chest pain and dyspnea on exertion for few months duration. Detailed imaging and laboratory investigation revealed a pericardial and mediastinal hydatid cyst. The patient underwent operation for curative excision. After surgery, the patient's symptoms resolved and his clinical status improved.
\end{abstract}

\section{Keywords}

Hydatid Disease, Echinococcus granulosus, Parasitic Infection, Zoonotic Disease

\section{Introduction}

Echinococcosis, commonly called as hydatid disease, hydatidosis or echinococcal disease is a parasitic infection of the tapeworm caused by echinococcal species. It is endemic in various geographical locations like Australia, Latin America, Eastern Europe, the Middle East and Africa [1]. Not much pervasive in the Indian subcontinent, it is commonly found in the states of Andhra Pradesh and Tamil Nadu [2]. The most common localization for hydatid cysts is liver (75\%), followed by lungs (15\%), spleen (5\%) and other organs (5\%) [3]. Rare hydatid cysts involving other organs like chest wall, mediastinal, pericardial, myocardial, lobar fissure and pleural locations are called intrathoracic extrapulmonary cysts [4] [5]. Of all intrathoracic extrapulmonary cysts, cardiac involvement is a very unusual presentation with an occurrence of about $0.5 \%-2 \%$ [6]. Till now three pathways have been proposed for migration of hydatid cysts to heart. In the first pathway involving portal vein, embryos 
which are smaller than $0.3 \mathrm{~mm}$ may pass through the sinus capillaries of the liver and, by way of the hepatic veins and vena cava, proceed to the right side of the heart and the pulmonary capillaries. In the next pathway, embryos enter the thoracic duct, internal jugular vein and right side of the heart through the lymphatics of the small intestine. The third possible route is through venal-venous anastomosis in the liver and the space of Retzius [7]. We report one such case of pericardial and mediastinal hydatid cyst in a female patient, who presented with chest pain and dyspnea on exertion for few months duration.

\section{Case Report}

A 57-year-old female housewife, from southern part of Odisha, presented with chest pain and dyspnea on exertion since last six months. Electrocardiogram showed T wave inversion in lead II, III, aVF and V3-V6 mimicking coronary ischemia (Figure 1). Her chest radiograph showed gross cardiomegaly \& mediastinal widening with a well defined, modulated, soft tissue dense mass in the mediastinum (Figure 2). Physical examination revealed prominent jugular veins. Echocardiogram revealed multiple anechoic cysts of varying size, along the posterior and lateral aspects of the left ventricle, extending upto its apex and compressing it (Figure 3). Coronary angiogram was normal. No interfering communication was noted between the cardiac cavity and the cysts. The cysts were inside the pericardium but outside the myocardium. CT \& MRI showed multiple septated cystic lesions of size $5-10 \mathrm{~cm}$, few with a calcified rim, involving the superior mediastinum in the right paratracheal region, posterior mediastinum in the right paraesophageal region, behind the right atrium and middle mediastinum, adjacent to the left ventricle in pericardial location, involving the pericardium and compressing the SVC and left border of heart, with no obvious invasion of major mediastinal vessels (Figure 4 \& Figure 5). Laboratory investigation revealed eosinophilia with positive hydatid serology.

Thoracotomy was performed to excise the cysts in the mediastinum and those attached to the pericardium followed by postoperative prophylaxis with oral albendazole. At 3-month follow-up, the patient was symptom free and without any postoperative recurrence.

\section{Discussion}

Echinococcosis is a parasitic zoonotic disease caused by the larval forms of Echinococcus species. Humans are accidently infested by ingesting food contaminated with parasite eggs. There are two species affecting the human population namely Echinococcus granulosus and Echinococcus multilocularis. It has a worldwide distribution and is endemic in regions where people follow traditional methods of livestock rearing and come in directcontact with cows, sheep and dogs. In India the disease is endemic in Kashmir, Andhra Pradesh, Tamil Nadu and Central India. The annual incidence varies from 1-200/105 persons [1].

Carnivores, mostly the dogs are definitive hosts for the adult $E$. granulosus, which harbor multitudes of adult tapeworms in their intestine and shed eggs and gravid proglottids, in their stools. Humans (intermediate hosts)

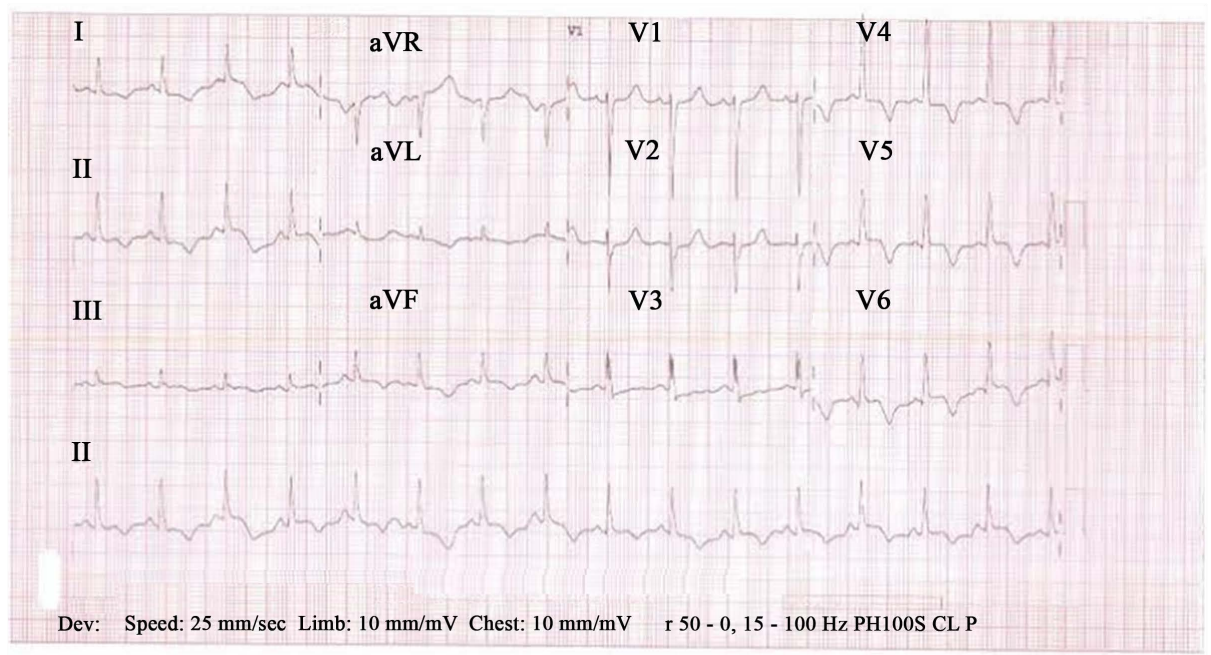

Figure 1. ECG showing T-wave inversion in II, III, AVF, and V3-V6 leads. 


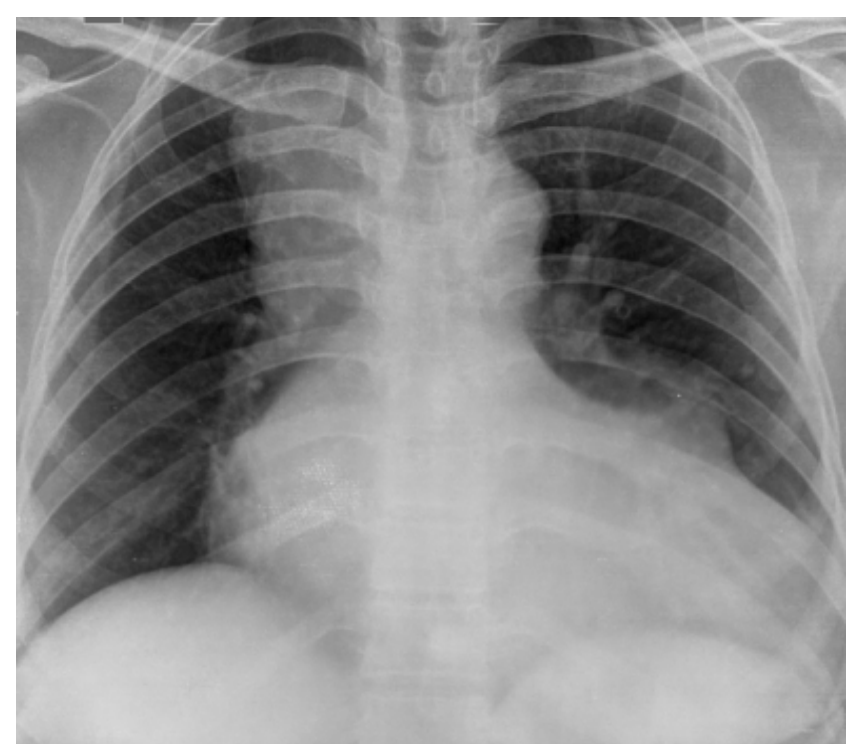

Figure 2. Chest radiograph showed gross cardiomegaly \& mediastinal widening.

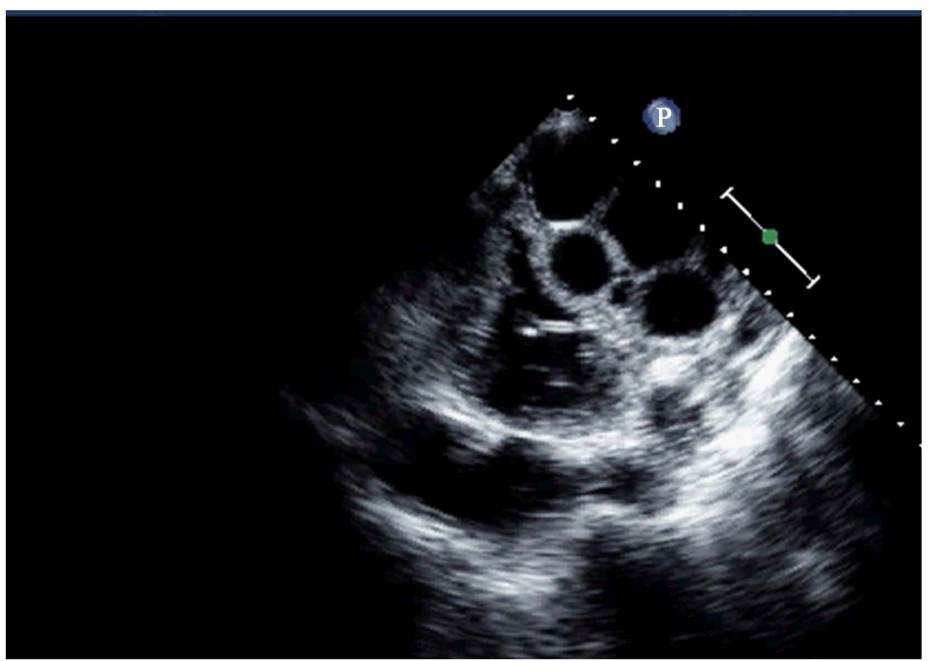

Figure 3. Echocardiogram revealing multiple anechoic cysts.

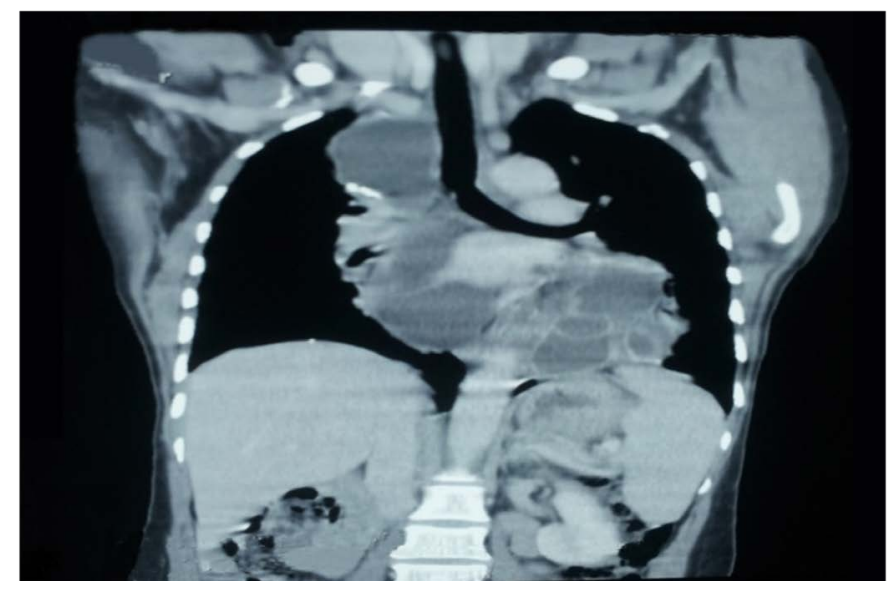

Figure 4. CT images of multiple, septated, cystic lesions. 


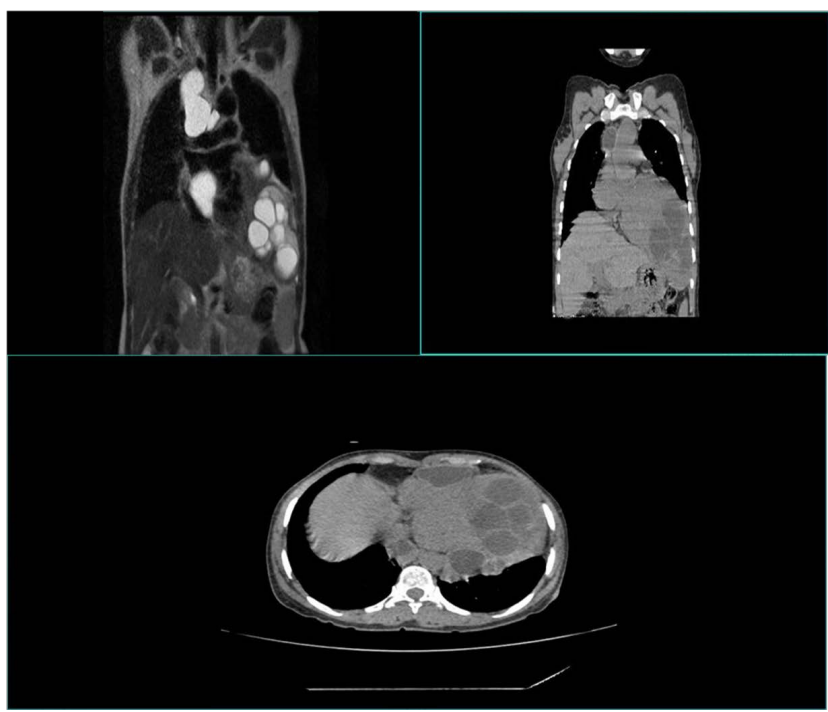

Figure 5. MRI images of multiple, septated, cystic lesions.

become infected by accidently swallowing these infective eggs. Its passage into the systemic circulation is responsible for diverse locations of the hydatid cysts. Liver and lungs act as blood filter for the dissemination of the parasite. Although echinococcal cyst is common in the liver \& lung, it can be encountered in any possible anatomical location. Intrathoracic extrapulmonary locations like the chest wall, mediastinum, pericardium, myocardium, lobar fissure, and pleura are rare even in endemic areas, and pose diagnostic and therapeutic problems. Despite the diverse locations, mediastinal localization of the hydatid cysts is very rare $(0.1 \%-0.5 \%)$. Commonest location is posterior mediastinum/paravertebral (55\%), followed by anterior mediastinum (36\%) and middle mediastinum (18\%). Localization may occur via transdiaphragmatic route, via an arterial branch of the thoracic aorta or via lymphatic or by postoperative dissemination from pulmonary cyst [8].

The clinical picture depends on the location and size of the cyst. Patients are usually asymptomatic, or may present with mild, recurrent, nonspecific chest pain, owing to pericarditis resulting from episodes of partial rupture into the pericardium, or external compression over the coronary artery [9]. Untreated cardiac cysts usually rupture into the cardiac chambers or pericardium causing pulmonary/systemic embolization, tamponade or anaphylactic shock. Constrictive pericarditis secondary to pericardial hydatid cyst has been reported [7].

Our patient was asymptomatic for many years after infection, and the first clinical symptom was chest pain and dyspnea. In addition to clinical symptoms and signs of relatively short duration, there were electrocardiographic changes that mimicked acute coronary ischemia. We believe that chest pain can exist in patients who have mediastinal or pericardial hydatid cysts, without any of the potential complications.

Diagnosis is based on typical clinical and radiographical criteria [10]. Imaging modalities like chest radiograph, USG, CT, and MRI play a vital role in the diagnosis and staging of mediastinal ecchinococcosis, However, it is neither radiologically nor clinically distinguishable from other mediastinal cystic lesions. 2-D echocardiography is the best diagnostic procedure to demonstrate a cardiac hydatid cyst. On echocardiography a well marginated, unilocular cyst with internal trabeculations corresponding to daughter cysts is diagnostic. The serologic diagnosis is not reliable, as it has high specificity, but low sensitivity in patients with intact cysts as the concentration of the antibody in serum is very low until the cyst leak.

The differential diagnoses of mediastinal cyst are still numerous even after cross-sectional imaging. These include thymoma, tuberculoma, necrotic carcinoma or abscesses in the anterior mediastinum, pleuro-pericardic cyst, cardiac tumors/masses in the middle mediastinum, bronchogenic cyst, enteric cyst, lymphangioma or neurogenic tumors in the posterior mediastinum. However, ecchinococcosis should be considered in the differential diagnosis of mediastinal cystic lesions especially in the endemic regions.

Treatment of choice for mediastinal hydatid cysts is radical resection of the germinative membrane with total pericystectomy. Partial pericystectomy is considered when the localization of the cysts and invasion of vital structures prevents the total excision. Prophylaxis with Albendazole has been used as an adjuvant to surgery to avoid recurrence and potential spread of the organism. 


\section{Conclusion}

Cardiac hydatid cyst should be considered in the differential diagnosis of patients who present with chest pain and dyspnea with shadow in chest X-ray. Intrathoracic extrapulmonary (mediastinal \& pericardial) location of hydatid cyst is rare, even in endemic countries, which makes initial diagnosis difficult. Diagnosis can be established based on the typical radiographic, echocardiographic signs findings and hydatid serology. CT/MRI are the main tools for diagnosis and the study of possible extension. Surgery is the best treatment and must be carried out early to prevent complications. Additional adjuvant medical therapy is essential to avoid recurrence. Prevention is still the best way to eradicate this parasite.

\section{References}

[1] Akther, M.J., Khanam, N. and Rao, S. (2011) Clinico Epidemiological Profile of Hydatid Diseases in Central India, a Retrospective \& Prospective Study. International Journal of Biological and Medical Research, 2, 603-606.

[2] Kayal, A. and Hussain, A. (2014) A Comprehensive Prospective Clinical Study of Hydatid Disease. ISRN Gastroenterology. http://dx.doi.org/10.1155/2014/514757

[3] Safioleas, M., Stamoulis, I., Theocharis, S., Moulakakis, K., Makris, S. and Kostakis, A. (2004) Primary Hydatid Disease of the Gallbladder: A Rare Clinical Entity. Journal of Hepato-Biliary-Pancreatic Surgery, 11, 352-356. http://dx.doi.org/10.1007/s00534-004-0915-6

[4] Gürlek, A., Dagalp, Z. and Özyurda, Ü. (1992) A Case of Multiple Pericardial Hydatid Cysts. International Journal of Cardiology, 36, 366-368. http://dx.doi.org/10.1016/0167-5273(92)90310-Y

[5] Miralles, A., Bracamonte, L., Pavie, A., Bors, V., Rabago, G., Gandjbakhch, I., et al. (1994) Cardiac Echinococcosis. Surgical Treatment and Results. The Journal of Thoracic and Cardiovascular Surgery, 107, 184-190.

[6] Ulgen, M.S., Alan, S., Karadede, A., Aydinalp, O. and Toprak, N. (2000) Cardiac Hydatid Cysts Located in Both the Left Ventricular Apex and the Intraventricular Septum: Case Report. Heart and Vessels, 15, 243-244. http://dx.doi.org/10.1007/PL00007271

[7] Isitmangil, T., Toker, A., Sebit, S., Erdik, O., Tunc, H. and Gorur, R. (2003) A Novel Terminology and Dissemination Theory for a Subgroup of Intrathoracic Extrapulmonary Hydatid Cysts. Medical Hypotheses, 61, 68-71. http://dx.doi.org/10.1016/S0306-9877(03)00108-7

[8] Eroğlu, A., Kürkçüoğlu, C., Karaoğlanoğlu, N., Tekinbaş, C., Kaynar, H. and Önbaş, Ö. (2002) Primary Hydatid Cysts of the Mediastinum. European Journal of Cardio-Thoracic Surgery, 22, 599-601. http://dx.doi.org/10.1016/S1010-7940(02)00398-6

[9] Murphy, T., Kean, B., Venturini, A. and Lillehei, C. (1971) Echinococcus Cyst of the Left Ventricle. Report of a Case with Review of the Pertinent Literature. The Journal of Thoracic and Cardiovascular Surgery, 61, 443.

[10] Shields, T. (2000) Mesothelial and Other Less Common Cysts of the Mediastinum. General Thoracic Surgery, 2 , 2423-2435.

\section{Submit or recommend next manuscript to SCIRP and we will provide best service for you:}

Accepting pre-submission inquiries through Email, Facebook, Linkedin, Twitter, etc A wide selection of journals (inclusive of 9 subjects, more than 200 journals)

Providing a 24-hour high-quality service

User-friendly online submission system

Fair and swift peer-review system

Efficient typesetting and proofreading procedure

Display of the result of downloads and visits, as well as the number of cited articles

Maximum dissemination of your research work

Submit your manuscript at: http://papersubmission.scirp.org/ 